\title{
ACHADOS FONOAUDIOLÓGICOS NA INSENSIBILIDADE CONGÊNITA A DOR COM ANIDROSE: RELATO DE CASO
}

\author{
Speech-language findings on pain congenital insensitivity with \\ anhydrosis: case report
}

\author{
Rosemere Teixeira Roza (1), Ana Lúcia de Magalhães Leal Chiappetta ${ }^{(2)}$
}

\begin{abstract}
RESUMO
Objetivo: relatar um caso de insensibilidade congênita a dor com anidrose de uma criança de 3 anos de idade, assim como discutir os achados fonoaudiológicos, em relação aos aspectos do sistema estomatognático, destacando-se o processo de reabilitação dos órgãos fonoarticulatórios. Métodos: relato de caso, baseado nos dados colhidos na anamnese, avaliação clínica, busca em prontuários e entrevista com responsável. Resultados: verificou-se um déficit considerável em todas as funções estomatognáticas, presença de lesões auto-mutilantes com perda tecidual em língua, lábios, mãos e dedos, o que acarretou uma desnutrição grave, quadros de anemia e freqüentes internações. Após intervenção fonoaudiológica, a paciente vem obtendo melhora nas funções acima afetadas, tonicidade dos órgãos fonoarticulatórios, regressão da desnutrição, anemia, auto-mutilação e traumas decorrentes da insensibilidade aos estímulos dolorosos. Conclusão: a terapia fonoaudiológica neste relato de caso é necessária pela possibilidade de retardar sintomas que aparecerão com a progressão da doença. Dessa maneira, a atuação precoce da fonoaudiologia em consonância com os demais profissionais da equipe de saúde, pode retardar a evolução do quadro clinico, visando uma melhor qualidade de vida para o paciente e para sua família.
\end{abstract}

DESCRITORES:Insensibilidade Congênita à Dor; Hipoidrose; Automutilação; Retardo Mental

\section{INTRODUÇÃO}

A Insensibilidade Congênita a Dor com Anidrose (CIPA) ou neuropatia sensorial autonômica hereditária tipo IV (NSAH IV) constitui-se em uma desordem de origem genética, autossômica recessiva, que afeta o sistema nervoso central e periférico. Vem sendo relatada como uma anomalia rara, no entanto, dados em relação a sua incidência não têm sido encontrados. Até 2001 , apenas 56 casos de CIPA haviam sido relatados na literatura médica ${ }^{1-4}$.

Esta neuropatia caracteriza-se clinicamente por episódios recorrentes de febre sem causa aparente, anidrose, ausência de reação à dor ou temperatura, comportamento auto-mutilador e retardo mental. Tais condições acontecem porque há uma falha na diferen-

(1) Fonoaudióloga do Departamento de Ortodontia e Odontopediatria da Faculdade de Odontologia da Universidade Federal do Rio de Janeiro; Especialista em Motricidade Oral pelo CEFAC - Saúde e Educação.

(2) Fonoaudióloga do Setor de Investigação em Doenças Neuromusculares da Universidade Federal de São Paulo; Doutora em Neurociências pela Universidade Federal de São Paulo. ciação e migração das células da crista neural, tendo como conseqüência à ausência de fibras desmielinizadas e diminuição das fibras mielinizadas menores, fazendo com que esses pacientes não apresentem reação à dor e temperatura. Além disso, suas glândulas sudoríparas não são inervadas, apesar de se apresentarem normais, levando assim à anidrose ${ }^{4-8}$.

O comportamento auto-mutilador pode se manifestar através de mordidas da língua e lábios, feridas nas mãos e dedos, fraturas, queimaduras, machucados e cortes. A ocorrência destas repetidas injúrias devido à insensibilidade à dor pode predispor o paciente a várias complicações, incluindo infecções, osteomielite, fraturas, deformações nas articulações e, menos comumente, amputações digitais, devendo o paciente ser monitorado e acompanhado por uma equipe multidisciplinar a qual inclui o fonoaudiólogo ${ }^{1,9}$.

$\mathrm{Na} \mathrm{CIPA}$, a consagüinidade é freqüentemente observada. Embora nenhuma desordem possua exatamente as mesmas características dessa doença, algumas neuropatias sensoriais apresentam aspectos semelhantes, já que a sensação de dor também é deficiente, tais como, Síndrome de Riley-Day e indi- 
ferença congênita a dor. Além disso, síndromes que apresentam comportamento auto-mutilador, como Síndrome de Lesch-Nyhan, podem ser determinantes para o diagnóstico diferencial da CIPA. Porém, esta última é a única neuropatia que o paciente acometido apresenta anidrose e febres recorrentes associada a um comportamento auto-mutilador ${ }^{2-4,6,9,10}$.

Devido à perda de reação à dor, um dos órgãos mais utilizados pelos pacientes para se auto-mutilarem são os dentes, o que resulta em risco de lesões à língua, lábios e mucosa oral, podendo ocasionar graves mutilações orais, como perda de tecido da língua. Na maioria dos casos, estes pacientes começam a morder sua língua ou dedos assim que seus dentes erupcionam. Além disso, danos decorrentes do comportamento auto-mutilador nas mãos e dedos, ou ainda remoção de unhas podem ocorrer em pacientes acometidos pela CIPA ${ }^{2,6,8,11,12}$.

As lesões traumáticas decorridas da auto-mutilação permanecem expostas ao trauma contínuo, podendo levar a um atraso na cicatrização e ao perigo de uma infecção superposta. Dessa forma, vários métodos têm sido utilizados para se evitar a auto-mutilação, tais como extrações dentárias, desgaste dental, uso de moldeiras ou uso de placa de proteção. Também é comumente relatada a perda precoce de dentes decíduos devido a trauma nestes pacientes, assim como auto-extrações dentárias ${ }^{2,8,10,13,14}$.

O diagnóstico precoce e preciso da doença é imprescindível, embora não haja tratamento específico. É necessário o acompanhamento de pacientes por uma equipe multiprofissional devido às complicações decorrentes da doença e para que sejam implementados programas especiais de treinamento na tentativa de se prevenir a auto-mutilação, diminuindo assim a gravidade $e$ a freqüência das injúrias traumáticas recorrentes ${ }^{1,3,6}$.

Dessa forma, o presente estudo objetiva relatar um caso de uma criança de três anos de idade com esta desordem, apresentando lesões auto-mutilantes em língua, mãos e dedos; assim como traçar o perfil fonoaudiológico, a partir dos achados, em relação aos aspectos do sistema estomatognático, destacando-se o processo de reabilitação dos órgãos fonoarticulatórios, que afetam o desempenho das funções alimentares de sucção, mastigação e deglutição e, ainda, das funções articulatórias e respiratórias.

\section{MÉTODOS}

Relato de caso de uma criança de três anos de idade com CIPA, baseado nos dados colhidos na anamnese (Figura 1), exame físico e avaliação clíni$\mathrm{ca}$, compreendendo os sinais e sintomas que interferem na função fonoaudiológica normal e, além disso, busca em prontuários e entrevista com responsável.

O presente estudo foi realizado na Associação de
Pais e Amigos dos Excepcionais (APAE), no município de Mendes/RJ, onde a criança é acompanhada desde o primeiro ano de vida. A elaboração desta pesquisa levou em consideração as recomendações da Resolução n 196/1996, do Conselho Nacional de Saúde, que incorpora, sob a ótica do indivíduo e das coletividades, os quatro referenciais básicos da bioética: autonomia, não maleficência, beneficência e justiça, entre outros.

O projeto desta pesquisa foi aprovado e considerado sem risco pelo Comitê de Ética em Pesquisa do Centro de Especialização em Fonoaudiologia Clínica sob o número 76/06 sendo necessária a apresentação do Termo de Consentimento Livre e Esclarecido.

\section{RESULTADOS}

\section{Relato de Caso}

Criança com três anos de idade, sexo feminino, nasceu de parto normal, a termo com 37 semanas de gestação. Baixo peso ao nascer $2.350 \mathrm{~g}$. Filha de pais consangüíneos (tio-sobrinha).

Segundo relatos da mãe, na primeira semana pósnatal, a criança apresentou episódios repetidos de febre com picos de $39^{\circ} \mathrm{C}$, com anidrose. A mesma percebeu que a temperatura corporal da filha aumentava quando a temperatura ambiente esquentava. $\mathrm{Na}$ segunda semana de vida, foi internada devido aos contínuos quadros febris, tendo recebido o diagnóstico médico de infecção urinária.

Durante uma internação hospitalar, aos sete meses de idade, devido à desnutrição e febre contínua, os médicos perceberam que a criança não chorava, não esboçava nenhuma expressão de dor, com estímulos dolorosos como punções de agulha. A mãe também já havia percebido que durante as imunizações injetáveis, a filha também não referia dor. Nesta mesma oportunidade, observou-se a presença de uma lesão no ventre da língua, que foi tratada como afta.

Repetidas ações auto-mutilantes e lesões traumáticas infectadas, além da febre alta, resultaram em freqüentes internações hospitalares para antibioticoterapia intravenosa. Seu peso, altura e perímetro cefálico eram inapropriados de acordo com sua idade. Sua pele estava sempre seca e morna à palpação, por causa da anidrose atribuída aos freqüentes quadros de hiperpirexia.

Aos nove meses, a criança foi retirada da mãe, devido a uma denúncia de maus-tratos. Pois a mesma, além do quadro de desnutrição grave que vinha apresentando, ainda exibia múltiplas lesões em língua, lábios, dedos e mãos decorrentes do comportamento auto-mutilador.

Com a persistência das lesões, a criança foi encaminhada para uma avaliação médica, ocasião em que a CIPA foi diagnosticada pela apresentação dos sintomas clínicos estereotipados, episódios repetidos de febre inexplicável, anidrose, auto-mutilação e 
insensibilidade a dor e a temperatura e retardo mental desde a infância. A insensibilidade à dor e à temperatura explicam o comportamento auto-mutilador, o aparecimento de lesões e até mesmo queimaduras freqüentes. Na maioria dos casos essas crianças começam a morder a língua ou os dedos quando os primeiros dentes erupcionam.

Desde então, a criança vem sendo acompanhada por uma equipe multiprofissional de saúde na APAE de MENDES/RJ e em caso de tratamentos de maior complexidade, esta é sempre encaminhada para uma referência mais próxima.

Após o diagnóstico de CIPA, a paciente foi submetida a uma avaliação fonoaudiológica da instituição e encaminhada ao Serviço de Odontopediatria da Faculdade de Odontologia da Universidade Federal do Rio de Janeiro, visto que as lesões auto-mutilantes eram, em sua maioria, provenientes de mordidas, dessa maneira o tratamento odontológico seria necessário.

Em sua avaliação inicial, foi observada uma extensa úlcera com aspecto necrótico na região de ventre da língua (Figura 2) e ferimentos em dedos, mãos, joelhos e pés (Figura 3). Apresentava também a dentição decídua completa e hígida, exceto pela ausência dos dentes 51 e 61, os quais haviam sido avulsionados devido a um trauma (queda) ocorrido, promovendo, segundo a mãe, a diminuição da lesão da língua.

Diante disso, o plano inicial de tratamento proposto pela odontóloga foi a utilização de moldeiras, mas não obteve êxito, visto que a criança a mordia e sua durabilidade não ultrapassava uma semana. Logo, foi proposta a exodontia de todos os elementos dentários, sob anestesia geral devido ao retardo mental e idade da paciente, além do seu comportamento não-cooperador. Porém, este procedimento foi contra-indicado pela equipe médica devido à desnutrição acentuada da mesma. Assim, as extrações foram realizadas em várias sessões, com intervalos de uma semana.

Ao longo do tratamento, observou-se regressão das lesões iniciais da língua, dedos e mãos, porém outras lesões passaram a ocorrer pelo desenvolvimento de novos comportamentos auto-mutiladores, como a remoção de unhas das mãos (Figura 4) e lesões em lábio e mucosa bucal (Figura 5). Esses novos hábitos foram implementados à medida que a paciente se adaptava $\mathrm{e}$ aprendia outras maneiras de se auto-mutilar com os dentes remanescentes entre as sessões. Após todas as exodontias, observou-se a cicatrização das lesões orofaciais e das lesões de mãos e dedos.

Durante todo esse processo, a paciente já nascida com baixo peso, passou a desnutrição grave com quadro de anemia, sujeita a diversos traumas e infecções, seja por conta da insensibilidade a dor e até mesmo a imunodepressão, atribuído à baixa ingesta alimentar, fato que se agravou devido à exodontia total. Visto isso, a intervenção fonoaudiológica seria essencial para o restabelecimento miofuncional dessa paciente, até porque a mesma apresentava déficit no desenvolvimento da fala, motor (tanto corporal quanto orofacial).

\section{Avaliação Fonoaudiológica}

Os achados fonoaudiológicos basearam-se na anamnese, no exame físico, clinico e entrevista com o responsável pela criança e demais profissionais que atuam em seu tratamento.

Ao exame físico: bochechas simétricas e espásticas; lábios interpostos em repouso e ausência de comissura labial. Língua alterada com perda de tecido glósseo, frênulo curto e presença de interposição lingual em repouso. Dentição iniciou-se com 6-7 meses de idade tendo sido submetida à exodontia total como tratamento de escolha pela odontopediatria. Frênulos labiais superior e inferior, palatos duro e mole sem alterações.

De início, a paciente utilizava a mamadeira como único instrumento para alimentação. O bico era redondo, de látex, com furo grande e tamanho médio. Durante a sucção a mesma conseguia sugar, porém com força muscular diminuída com ausência de movimentação das bochechas e escape extra-oral considerável.

O canudo está começando a ser introduzido na estimulação fonoaudiológica, pois até o momento a paciente não apresentava a força de sucção necessária para este utensílio. O vedamento labial estava ausente, escape de líquido presente, pouca movimentação de bochechas e ausência de aumento de tônus corporal durante a função.

Outros utensílios, como copos e colheres foram introduzidos no sentido de desenvolver as funções estomatognáticas que se encontravam subdesenvolvidas e até mesmo ausentes. O início foi complicado pela pouca ou quase nenhuma habilidade que a paciente segurava os novos utensílios. O alimento era retirado da colher, virando-a e raspando-a na gengiva e/ou lábio inferior, com presença do reflexo de mordida tônica. Amovimentação das bochechas era quase nula. Ao utilizar o copo, a mesma não vedava o lábio corretamente, o apoio era feito na gengiva devido à ausência dos dentes, com presença de escape extra-oral de liquido.

Quando iniciaria a avaliação da mastigação, percebeu-se a incoordenação de movimentos de lábios, língua e mandíbula associados a movimentos da cabeça. A paciente não lateralizava, projetava e nem apresentava rotação da mandíbula. Pouca movimentação das bochechas foi observada, com amplitude vertical mandibular aumentada, falha na trituração dos alimentos, com apenas o amassamento pela língua contra o palato duro e escape extra-oral significativo.

No que se refere à deglutição, a mesma apresentava escape extra-oral, escape abundante de saliva, dificuldade para deglutir tanto sólidos quanto pasto- 
sos e tempo de refeição maior que 30 minutos. Às vezes apresentava engasgos, tosse, recusa alimentar e histórico de pneumonias.
Quanto à respiração, esta se apresentava mista (oral e nasal), com ciclos curtos, às vezes ruidosa e, predominantemente, abdominal.

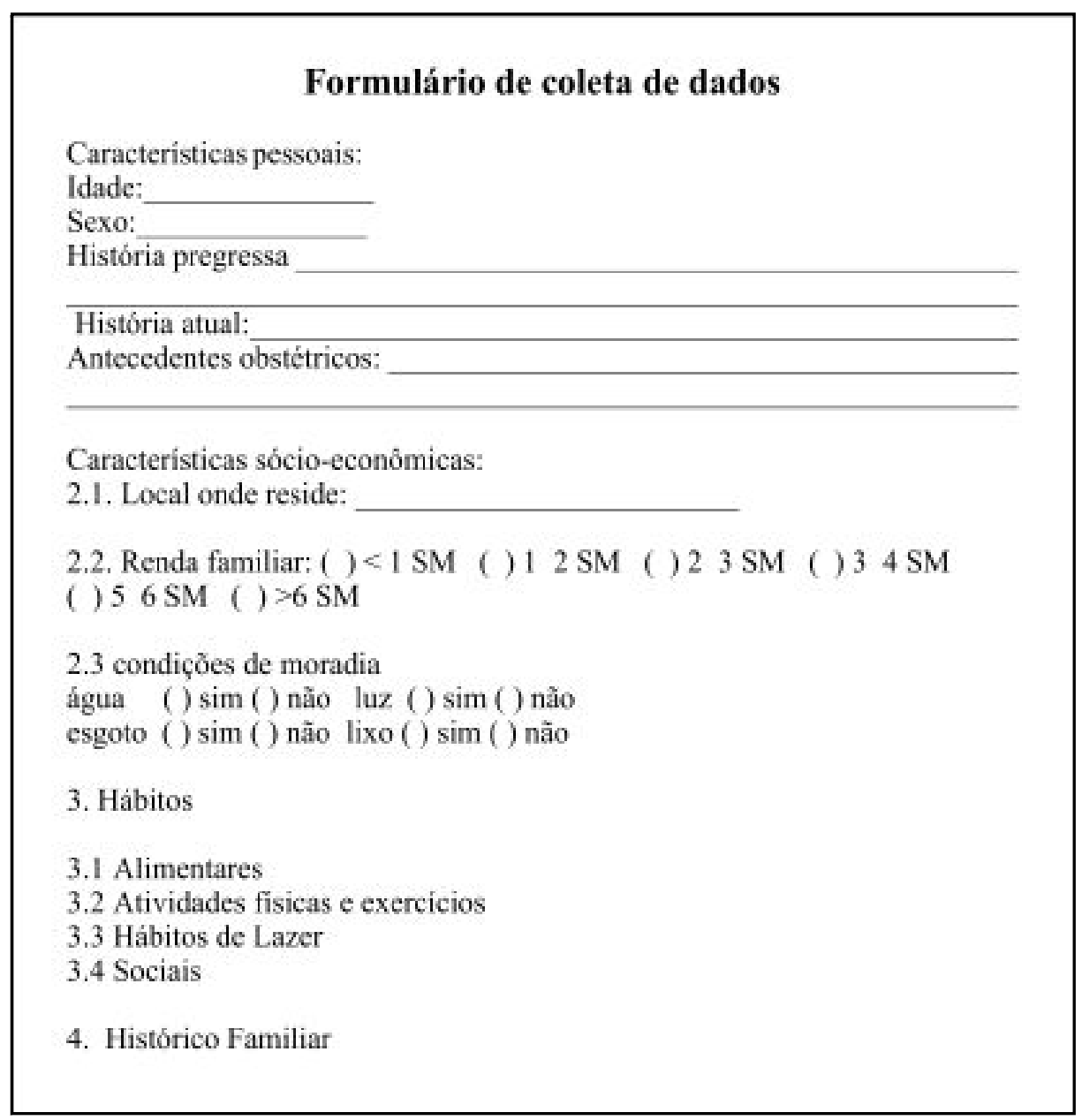

Figura 1 - Formulário de coleta de dados utilizado na anamnese da criança

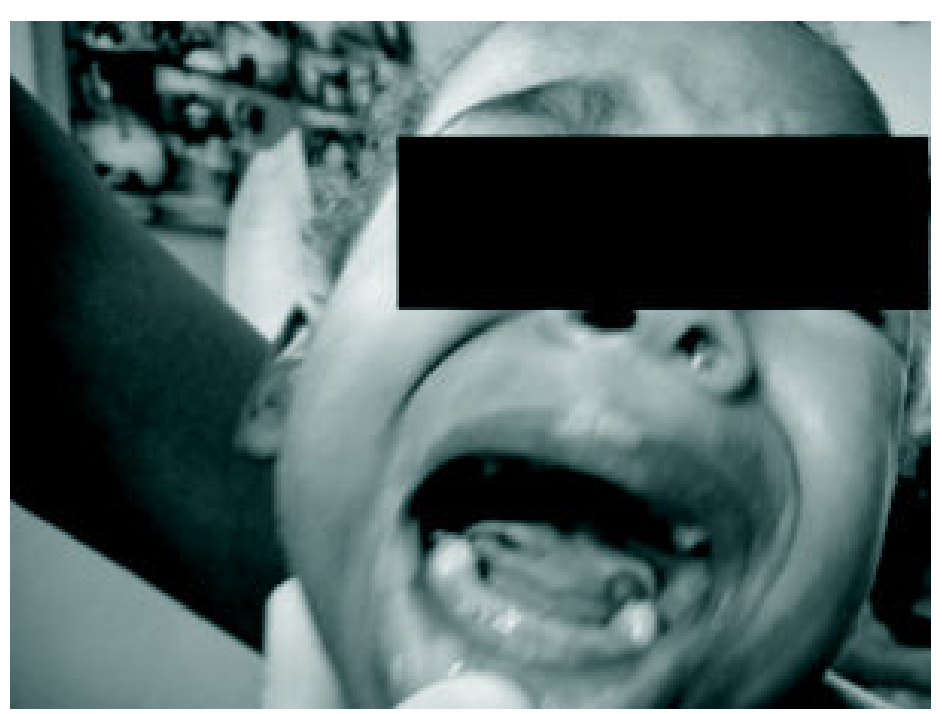

Figura 2 - Lesão em dorso de língua com perda de tecido glósseo. Inicio da exodontia 


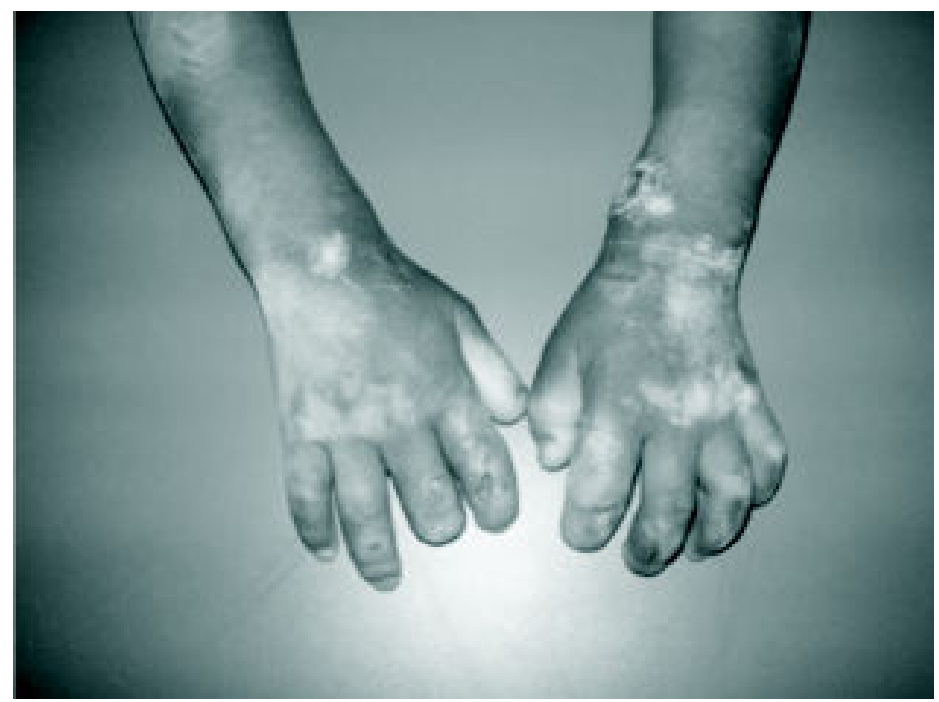

Figura 3 - Lesões auto-mutilantes em dedos e mãos. Nota-se a perda da falange distal do $3^{\circ}$ quirodáctilo direito

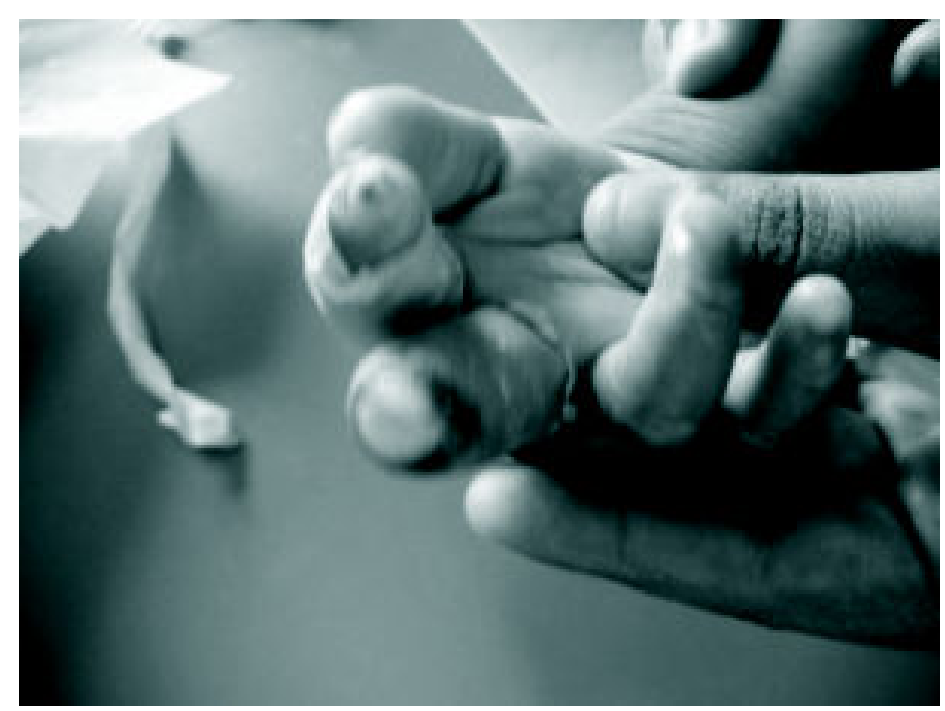

Figura 4 - Lesões provenientes de novo comportamento auto-mutilador: remoção das unhas como reação à exodontia

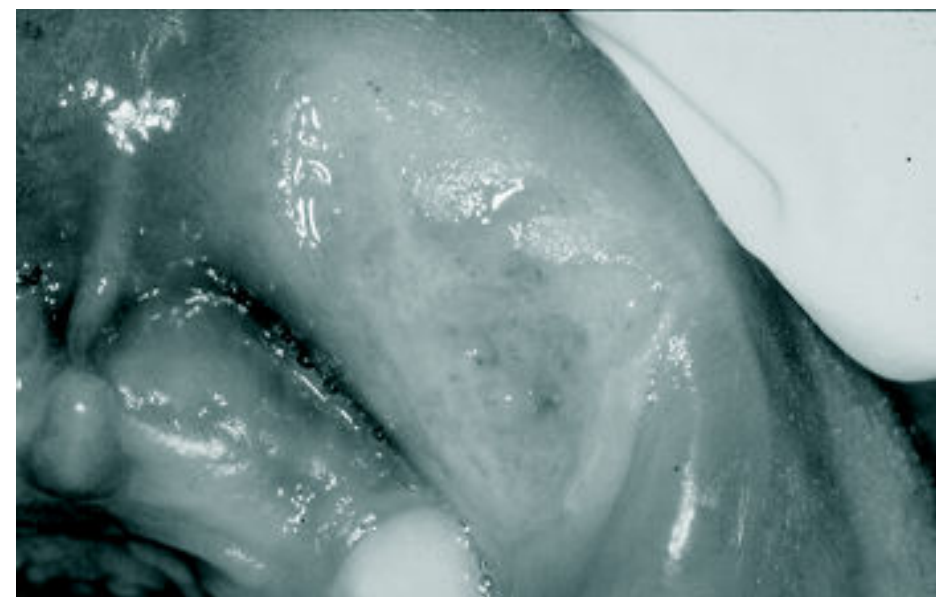

Figura 5 - Lesão ulcerada em lábio inferior durante o processo de exodontia, as lesões em língua regrediram dando origem as novas lesões em lábios 


\section{DISCUSSÃO}

A Insensibilidade congênita a dor com anidrose (CIPA) apresenta um quadro clínico estereotipado, geralmente os pacientes têm episódios inexplicáveis de hiperpirexia no período pós-natal ou na infância, anidrose, auto-mutilação e insensibilidade à dor e à temperatura e retardo mental desde a infância. A insensibilidade à dor e à temperatura explicam o comportamento auto-mutilador e queimaduras freqüentes. Na maioria dos casos, essas crianças começam a morder a língua ou os dedos quando os dentes erupcionam ${ }^{6}$.

As pessoas afetadas por esta síndrome geralmente morrem na infância devido a quadros de hiperpirexia e falha na percepção das injúrias e processos dolorosos, visto que a capacidade de perceber a dor tem um grande valor para a sobrevivência ${ }^{6-9}$.

Traumas na língua são a manifestação oral mais freqüente nesta condição, assim como, no lábio inferior. Danos extensos nas mãos e dedos são resultado de mordidas freqüentes e auto-mutilação ${ }^{15}$.

Há relatos na literatura sobre a atribuição de maus-tratos a essa doença e a consangüinidade é freqüentemente observada. Estes achados também foram evidenciados neste estudo, uma vez que a criança era filha de pais consangüíneos e exibia traumas repetidos e danos com perda tecidual sem explicação, antes do diagnóstico de CIPA $^{2-4,10}$.

Dessa forma, vários métodos têm sido utilizados para se evitar a auto-mutilação, tais como extrações dentárias, desgaste dental, uso de moldeiras ou uso de placa de proteção ${ }^{8,10,13,14}$.

O tratamento de escolha para o caso relatado foi a exodontia total, pois a utilização de moldeiras não obteve êxito, devido a constantes mordidas e desgaste da mesma, pela paciente, que reduzia sua durabilidade para aproximadamente uma semana. Com a exodontia, a paciente que já apresentava baixo peso desde o nascimento, teve uma piora do quadro de desnutrição e anemia, devido à baixa ingesta alimentar.

Frente às dificuldades da função de sucção que a paciente apresentou, a intervenção fonoaudiológica foi necessária, no sentido de restabelecer esta função estomatognática. O furo do bico da mamadeira, que era grande, foi ajustado de acordo com sua idade, com o objetivo de demandar maior força da criança ao sugar, e dessa maneira aumentar o tônus muscular, isto foi observado pelo início da movimentação das bochechas após algumas sessões, além disso, o bico de látex e redondo foi substituído pelo ortodôntico e siliconizado.

No que tange as funções de mastigação, deglutição e respiração, a intervenção fonoaudiológica tem sido bastante pontual e incisiva. A reabilitação dessas funções vem proporcionando a esta cliente uma melhora em seu quadro clinico, principalmente no que se refere à desnutrição, fato que tem sido observado com o ganho ponderal após o inicio do tratamento. A educação da paciente e de seus familiares tem sido um fator essencial na continuidade da assistência multiprofissional.

Percebe-se que com a adesão da família e do próprio paciente, o processo de reabilitação torna-se mais eficaz e eficiente, pois quando a família desconhece o motivo pelo qual deve ou não realizar uma atividade/exercício qualquer, não há um engajamento total ao tratamento, e em alguns casos, o descaso e a incredulidade, podem estar presentes. Assim, o quanto antes os pais forem orientados e iniciado o tratamento precoce, melhores são as chances de uma criança com CIPA desenvolver-se sadiamente como outras crianças.

O acompanhamento contínuo torna-se necessário, pois se espera que com o aumento da idade e a intervenção fonoaudiológica, o comportamento auto-mutilador do paciente melhore, como observado em caso relatado na literatura ${ }^{16}$.

O diagnóstico precoce e preciso da doença é imprescindível, embora não haja tratamento específico. É necessário o acompanhamento de pacientes por uma equipe multiprofissional devido às complicações decorrentes da doença e para que sejam implementados programas especiais de treinamento na tentativa de se prevenir a auto-mutilação, diminuindo assim a gravidade e a freqüência das injúrias traumáticas recorrentes $^{1,3,6}$.

\section{CONCLUSÃO}

Conclui-se que a terapia fonoaudiológica neste caso de insensibilidade congênita a dor com anidrose é importante, apontando para a possibilidade de retardar sintomas que aparecerão com a progressão da doença. Durante o período em que a paciente iniciou o tratamento foi evidenciada a melhora do processo de alimentação, ganho ponderal, incluindo a reabilitação dos órgãos fonoarticulatórios, bem como a diminuição da automutilação e traumas decorrentes da insensibilidade aos estímulos dolorosos. Dessa maneira, a atuação precoce da fonoaudiologia em consonância com os demais profissionais da equipe de saúde pode retardar a evolução do quadro clinico, visando uma melhor qualidade de vida para o paciente e para sua família. 


\begin{abstract}
Purpose: case report of congenital insensitivity to pain with anhydrosis of a 3-year-old child as well as discussing the speech-language findings, in relation to the aspects of the stomatognathic system, highlighting the process of rehabilitation for speech and hearing organs. Methods: case report, based on the data gathered in the anamnesis, clinical evaluation and interviews with child's parents. Results: a considerable deficit was verified in all the stomatognathic's function, presence of self-mutilation behavior with loss tissue in tongue, lips, hands and fingers that gave rise to a severe malnutrition, anemia pictures and frequent hospital internments. After the speech-language pathologist therapy program the patient has been obtaining improvement in the aforementioned affected functions, tonicity of the speech and hearing organs, and regression of malnutrition, anemia, self-mutilation and current traumas of the insensibility to the painful stimulus. Conclusion: the speech-language therapy in this case report is important, pointing out for the possibility of delaying symptoms that will appear with the progression of the disease. In that way, the early performance of the speech-language pathologist in consonance with the other health professionals, may retard the evolution of the clinical picture, seeking a better quality of life for the patients and for their family.
\end{abstract}

KEYWORDS: Pain Insensitivity, Congenital; Hypohidrosis; Self Mutilation; Mental Retardation

\section{AGRADECIMENTOS}

À Direção e equipe técnica da Associação de Pais e Amigos dos Excepcionais (APAE) de Mendes/RJ, pela autorização do estudo nesta instituição; à família e à criança envolvida neste estudo, pela participação na pesquisa e às odontólogas: Glória Fernanda Barbosa de Castro (Professora Pesquisadora ProDoc-CAPES-UFRJ) e Beatriz Gonçalves Neves (Mestranda em Odontopediatria, FO-UFRJ) pelo auxilio odontopediátrico.

\section{REFERÊNCIAS}

1. Berkovitch M, Copeliovitch L, Tauber T, Vaknin Z, Lahat $E$. Hereditary insensitivity to pain with anhidrosis. Pediatr Neurol. 1998; 19(3):227-9.

2. Erdem TL, Ozcan I, Ilguy D, Sirin S. Hereditary sensony and autonomic neuropathy: review and a case report with dental implications. J Oral Rehabil. 2000; 27(2):180-3.

3. Toscano E. Hereditary sensory and autonomic neuropathy type IV. Orphanet Encyclopedia. 2003. 4. Shorer Z, Moses SW, Hershkovitz E, Pinsk V, Levy J. Neurophysiologic studies in congenital insensitivity to pain with anhidrosis. Pediatr Neurol. 2001; 25(5):397-400.

5. Rosemberg S, Marie SK, Kliemann S. Congenital insensitivity to pain with anhidrosis (hereditary sensory and autonomic neuropathy type IV). Pediatr Neurol. 1994; 11(1):50-6.

6. Kim JS, Woo YJ, Kim GM, Kim CJ, Ma JS,
Hwang TJ, Lee MC. Congenital insensitivity to pain with anhidrosis: a case report. J Korean Med Sci. 1999; 14(4):460-4.

7. Nolano M, Crisci C, Santoro L, Barbieri F, Casale R, Kennedy WR, Wendelschafer-Crabb G, Provitera V, Di Lorenzo N, Caruso G. Absent innervation of skin and sweat glands in congenital insensitivity to pain with anhidrosis. Clin Neurophysiol. 2000; 111(9):1596-601.

8. Bonkowsky JL, Johnson J, Carey JC, Smith AG, Swoboda KJ. An infant with primary tooth loss and palmar hyperkeratosis: a novel mutation in the NTKR1 gene causing congenital insensitivity to pain with anhidrosis. Pediatrics. 2003; 112(3):e237-41.

9. Nagasako EM, Oaklander AL, Dworkin RH. Congenital insensitivity to pain: an update. Pain. 2003; 101(3):213-9.

10. Yagev R, Levy J, Shorer Z, Lifshitz, T. Congenital insensitivity to pain with anhidrosis: ocular and systemic manifestations. Am J Ophthalmol. 1999; 127(3):322-6.

11. Brahim JS, Roberts MW, McDonald HD. Oral and maxillofacial complications associated with congenital sensory neuropathy with anhydrosis: report of two cases. J Oral Maxillofac Surg. 1987; 45(4):331-4.

12. Gadoth N, Mass E. Hereditary neuropathies with self-mutilation. J Pediatric Neurology. 2004; 2:205-11.

13. Amano A, Akiyama S, Ikeda M, Morisaki I. Oral manifestations of hereditary sensory and autonomic neuropathy type IV. Congenital insensitivity to pain with anhidrosis. Oral Surg Oral Med Oral Pathol 
Oral Radiol Endod. 1998; 86(4):425-31.

14. Ku AS, Rodrigo CR, To PCY. Anesthetic management of a child with congenital insensitivity to pain with anhydrosis. J Oral Maxillofac Surg. 2005; 63(6):848-51.

15. Littlewood SJ, Mitchell L. The dental problems and management of a patient suffering congenital insensitivity to pain. Int J Paediatr Dent. 1998; 8(1):47-50.

16. Kouvelas N, Terzoglou C. Congenital insensitivity to pain with anhidrosis: case report. Pediatr Dent. 1989; 11(1):47-51.

RECEBIDO EM: 22/06/2006

ACEITO EM: 22/05/2007

Endereço para correspondência:

Rua da Capela, 47

Rio de Janeiro - RJ

CEP: $26700-000$

Tel: (21) 22457752

E-mail: rosefono2003@yahoo.com.br

Rev CEFAC, São Paulo, v.9, n.3, 367-74, jul-set, 2007 